\title{
Cycle time reduction in manufacturing industry by designing a dedicated fixture: A case study
}

\author{
B. Lathashankar ${ }^{*}$, G. Ashritha ${ }^{2}$, S. Asma ${ }^{2}$, K. Shivam ${ }^{2}$, K. Nitesh ${ }^{2}$ \\ ${ }^{1}$ Department of Industrial Engineering and Management, Siddaganga Institute of Technology, Tumkur, INDIA \\ ${ }^{2}$ Department of Industrial Engineering and Management, Siddaganga Institute of Technology, Tumkur, INDIA \\ "Corresponding Author: e-mail: blshankar@sit.ac.in, Tel +91-9964505469
}

\begin{abstract}
The principal commercial requirement of any manufacturing system is directed towards a growth in productivity. One of the options for achieving higher productivity is reducing the cycle time. Cycle time comprises of the following time element: operation, loading/unloading, set-up and idleness. In this work a case study of a reputed construction equipment manufacturing company of India is considered where in it was observed that the demand for the 4Ton compactors remained unmet as there were no dedicated fixtures for the tack welding operation of those compactors. This welding work was being performed using hook and carrier by trial and error method. This led to inefficient utilization of man, machine, money and increase in manufacturing time. So there was a need to design the dedicated fixture so as to reduce the cycle time of tack welding operation. Benefits of this new fixture are twofold. It reduces setup time because it eliminates marking for each job, positioning by trial and error method and hence increases the productivity of 4 Ton compactor. Also, usage of fixture calls for semiskilled labor instead of skilled labor, reducing labor cost for improved production rate.
\end{abstract}

Keywords: Productivity, compactor, fixture, setup time, cycle time

DOI: http://dx.doi.org/10.4314/ijest.v10i3.4

\section{Introduction}

The manufacturing cycle time of a job is the total time required to convert raw materials into finished products. It is comprised of operation time, loading/unloading time, setup time and idle time. Out of these, only during operation time value addition takes place and the loading/unloading, setup and idle times come under the label 'downtime'. Downtime per job unit can be reduced by increasing batch quantity, or by reducing the set up/machine idle times. Down time and hence the cycle time reduction is considered as the one of best options as an industry attempts to enhance productivity, cut down cost with customer response time (Han et al., 2013).

This work contributes to cycle time reduction of tack welding processes done for front chassis and rear chassis of 4T compactor and carried out at a reputed construction equipment manufacturing company of India. Compactor is a mechanism employed to lessen the dimension of substances, for instance, waste substance or biomass by compressing or pressing. It is as well referred to as road roller in construction sites and employed to compress concrete, gravel, soil and others to construct roads and prepare foundations. There are different types of compactors based on purpose and operating weights. Operating weight of $4 \mathrm{~T}$ compactor is 3.65 Tons and hence the name 4T compactor.

American Welding Society A3.0 Standard Terms and Definitions defines tack weld as "A weld made to hold the parts of weldment in proper alignment until the final welds are made." Thus tack welding refers to temporary joining process used to create the initial joint between two pieces of metal to be welded together. (Miller, 2003).

A fixture is a work-grasping and supporting piece of equipment employed in mechanical industry. Fixtures are employed to firmly position and sustain the work, making certain that every part created by employing the fixture will uphold compliance and exchange. Diverse fundamentals of a fixture are, 
- Locator: A locator is a fixed component employed to institute and upholds the location of a part in the fixture through restraining the part's movement.

- Clamp: A clamp is a force-activating fixture's device. The forces put forth through the clamps grasp a part firmly in the fixture opposed to every other exterior force.

- Support: A support is a permanent or adaptable fixture's element. As critical part dislocation/re-direction is predictable subject to the engagement of obligatory fastening and dispensation forces, props are appended and located underneath the work member in order to avoid deformation.

- Fixture Body: Fixture body is the most important structural constituent of a fixture. It preserves the spatial association between the fixturing constituents and the machine tool on which the part is to be dealt with.

In this work an attempt is made to design and model a dedicated fixture for tack welding operation of front and rear chassis. Design of the fixture is based on 3-2-1 principle and modeled using CATIA V5 R20 modeling software. Once the broad area of study was chosen, a survey of related work done in the literature was studied. The outcomes of some pertinent studies on the cycle time reduction are summarized in Table 1 .

Table 1. Outcomes of some pertinent studies on the cycle time reduction

\begin{tabular}{|c|c|c|}
\hline Sl. No. & Reference & Objective \\
\hline 1. & Antil et al., 2013 & $\begin{array}{l}\text { By modifying the tool and fixture, rejection rate was reduced and the production was } \\
\text { increased. }\end{array}$ \\
\hline 2. & Shayea et al., 2011 & $\begin{array}{l}\text { A representation was built up that minimizes the productivity of the process of producing } \\
\text { goods while minimizing the operation's risk and fatigue }\end{array}$ \\
\hline 3. & $\begin{array}{l}\text { Deshmukh \& Humbe, } \\
2014\end{array}$ & $\begin{array}{l}\text { Though six sigma is a powerful tool to quality improvement, technical expertise alone } \\
\text { cannot yield results without the working environment and top management support. }\end{array}$ \\
\hline 4. & $\begin{array}{l}\text { Naveen \& Ramesh } \\
\text { Babu, } 2015\end{array}$ & $\begin{array}{l}\text { Cause and effect chart was employed to establish the cause that limits the rate of } \\
\text { production and the corrective approaches have been proposed }\end{array}$ \\
\hline 5. & Mishra R, 2015 & Productivity improvement was achieved through method study principles \\
\hline 6. & Malik et al., 2011 & $\begin{array}{l}\text { After implementing industrial engineering techniques for cycle reduction, production time } \\
\text { was reduced by } 24 \% \text {. }\end{array}$ \\
\hline 7. & Mengawade et al., 2016 & Review paper producing an analysis of work holding fix time and design \\
\hline 8. & Vinay et al., 2015 & Fixture is designed for compactor and results are analyzed using CATIA software \\
\hline 9. & Oroumieh et al., 2013 & $\begin{array}{l}\text { The employment of fuzzy logic as well as neural is made to choose the adequate } \\
\text { integration of wring area, engine thrust and the weight of aircraft design }\end{array}$ \\
\hline 10. & Diop et al., 2017 & $\begin{array}{l}\text { Put forward a new policy in exchange of natural gas waste heat brought out from the exit } \\
\text { point of the recuperator, producing superior energy reduction as well as lessening the heat } \\
\text { treatment cycle time }\end{array}$ \\
\hline 11. & Muvunzi et al., 2018 & $\begin{array}{l}\text { A representation to forecast the cycle time for a procedure involving hot stamping is } \\
\text { contributed using the process of heat capacitance and the finite element simulation was } \\
\text { used to validate it }\end{array}$ \\
\hline 12. & $\begin{array}{l}\text { Santhosh Kumar et al., } \\
2014\end{array}$ & $\begin{array}{l}\text { Treated the investigation of the present operation time in assembling and line balancing, } \\
\text { to escape delay at workstations while lean tools were implemented, yielding a reduction of } \\
\text { cycle time for an assembly line }\end{array}$ \\
\hline 13. & Diaz et al., 2017 & $\begin{array}{l}\text { Focuses on cycle time study for an aircraft assemblage with a case study drawn from a } \\
\text { wing spar to discover possible aspects for productivity enhancement and suggest novel } \\
\text { solutions, which could lessen the cycle time by } 20 \% \text {. }\end{array}$ \\
\hline 14. & Wang et al., 2016 & $\begin{array}{l}\text { Evaluates the deposit elimination ratio in the Electrolyzed oxidizing water cleaning-in- } \\
\text { place procedure employing a stainless steel surface appraisal simulator and develops the } \\
\text { model for same. }\end{array}$ \\
\hline
\end{tabular}

\section{Problem Definition}

Achieving higher productivity requires a reduction in downtime of job in manufacturing. One of the options to accomplish this is by the use of correct fixture that helps in minimizing setup time during manufacturing. It was observed at the manufacturing site that the demand for the 4Ton compactors remained unmet as there were no dedicated fixtures for the tack welding operation of those compactors. This welding work was being performed using hook and carrier by trial and error method. This lead to inefficient utilization of man, machine, money and resulted in increase in manufacturing lead time. So there was a need to design the fixture in order to lessen the cycle time that will afterwards enhance productivity. 


\section{Methodology}

As soon as the problem was observed and the project objectives spelt out, the subsequent step was to examine the current procedure of the tack welding function carried out in the manufacturing of compactor. Important components of the compactor related to tack welding are front chassis, rear chassis and roller drum. These are shown in Figure 1. The chief challenge confronted in the course of the tack welding function of chassis was excessive time consumed by the loading and unloading activities of the components onto the chassis and the was an absence of dedicated fixtures. In addition, the component alignment was carried out by evaluating the dimensions repeatedly, and fixing it by trial and error approach, and no systematic approaches were employed. The needed data was gathered through evaluating the dimensions of different components and documented. The time in use for the welding function of each chassis' component was as well documented. After that, the cycle time for the front chassis and the rear chassis were 450 and 510 minutes, correspondingly. This was well thought-out to be elevated and it was unable to cope with the growing customer demand.

3.1 Fixture design: Fixture was designed based on 3-2-1 principle which describes about the degrees of freedom in the design. Any free body has a total of twelve degrees of freedom. Six translational degrees of freedom, namely; $+\mathrm{X},-\mathrm{X},+\mathrm{Y},-\mathrm{Y},+\mathrm{Z},-\mathrm{Z}$ and 6 rotational degrees of freedom, namely; clockwise and anticlockwise around $\mathrm{X}, \mathrm{Y}$ and $\mathrm{Z}$ directions. All the 12 degrees of freedom must be fixed except the three transitional degrees of freedom $(-X,-Y$ and $-Z)$ in order to locate the workpiece in the fixture. So, nine degrees of freedom of the work piece are needed to be fixed.

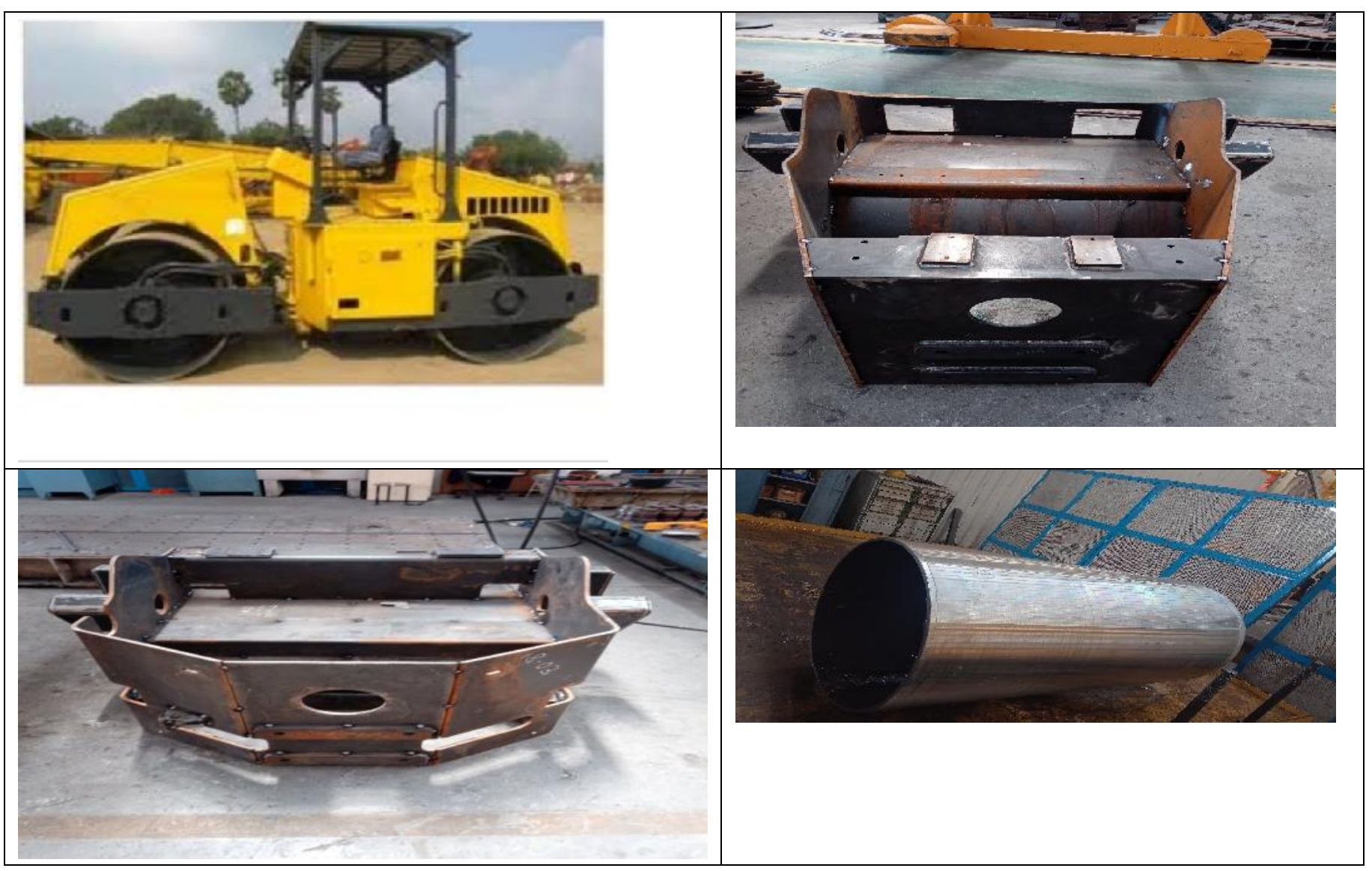

Figure 1(a). 4Ton Compactor. (b). Front chassis. (c). Rear chassis. (d). Roller drum

Following five step procedure was followed in designing the fixture:

- Fixture Planning: Proper plan of fixture design was made so that project objectives were achieved.

- Fixture Layout: It represents the fixture's concepts in a physical form. It included positions and types of locators, clamps and supports, if any.

- Fixture element design: In this step either detail drawings of elements of fixture were considered on paper or solid models were created. 
- Fixture body design: Here a rigid structure carrying all the individual fixtures elements in their proper places would be made ready.

- Evaluation, approval and completion of design: Lastly, the design was evaluated and later approved by the higher authority

\section{Results and Discussion}

Once the design of the fixture was ready based on 3-2-1 principle it was generated using CATIA V5 R20 modeling software. A brief explanation of designed fixture, element wise, is given below;

Pillars: Pillars are the vertical components of the fixture. There are 4 pillars each for front and rear chassis supporting the structure from 4 different directions. Out of these 4 pillars, 2 pillars are stationary and the other 2 are adjustable in horizontal direction. 2D and 3D drawings of the pillar are shown in Figures 2(a) and (b).
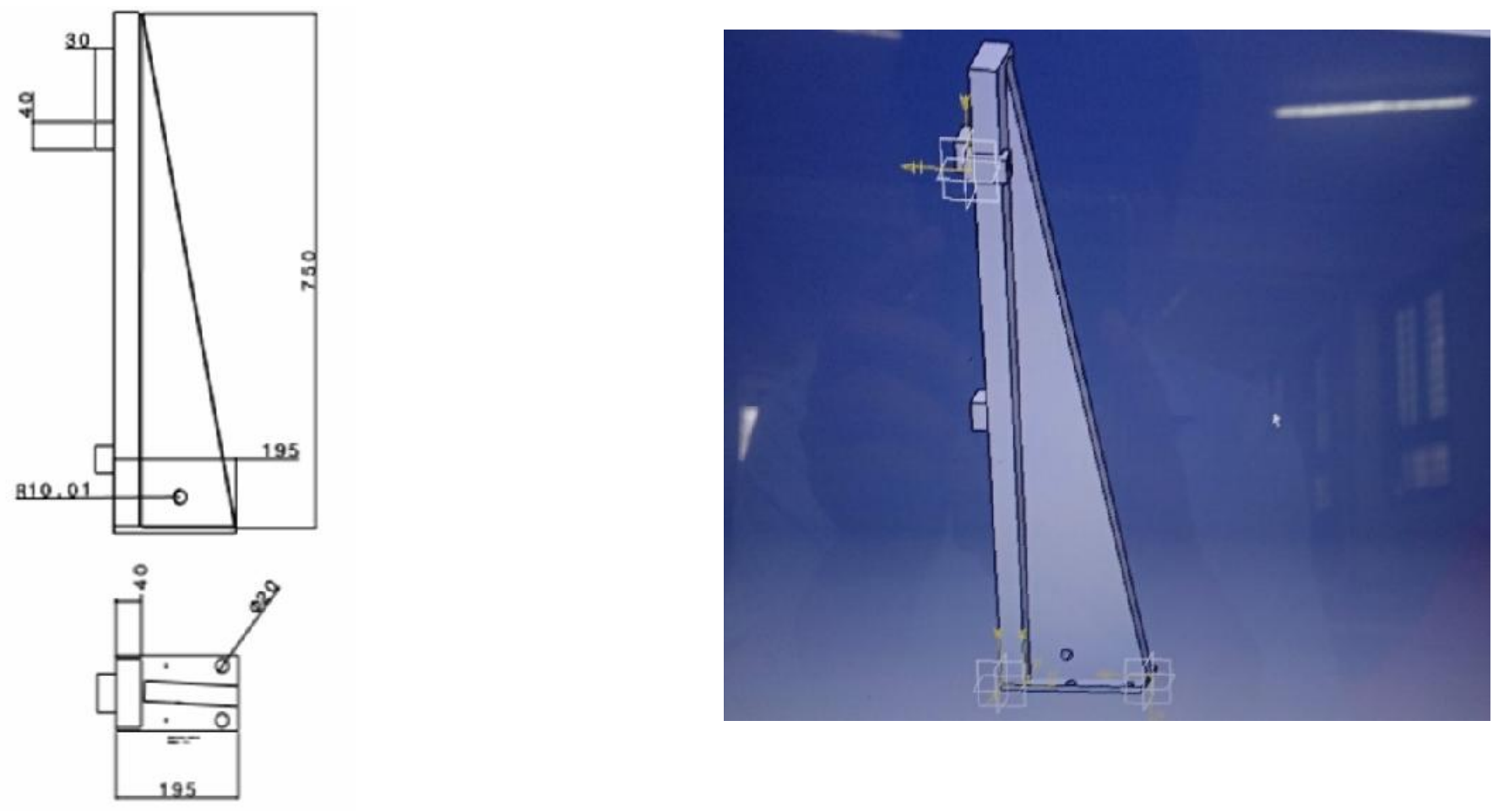

Figure 2(a). 2D drawing of pillar, (b). 3D drawing of pillar

Clamp: Clamp is the supporting device employed to sustain and confine the advance of the work material. It is a block of rectangular shape comprising of holes on two surfaces. The screw rod passing by the holes, offers hold to the arrangement. 2D and 3D drawings of the Clamp are shown in Figures 3(a) and (b).

Drum cover plate: This is prepared as a void block to lessen the material's weight. It is a void hemisphere by means of a cutting cord on the further side. The two- and three-dimensional drawings of the drum cover plate are shown in Figures 4(a) and (b).

Slider: It is the method employed to cause the pillar modifiable in the parallel course as well to effortlessly get rid of the mechanisms from the fixture. The two- and three-dimensional drawings of the slider are shown in Figures 5(a) and (b).

Support: This is in the outline of an L-wedge offered to sustain the back plate of the face chassis and face plate of the back chassis. It includes 2 rectangular wedges of unequal thickness. These wedges enclose 4 holes as revealed in the Figures 6(a) \& (b) for front chassis and in the Figures 7(a) \& (b) for rear chassis.

Fixture: $2 \mathrm{D}$ and 3D drawings of proposed fixtures for front chassis of the 4T compactor are shown in the Figures 8 and 9 respectively. Also these drawings for those for rear chassis are shown in Figures 10 and 11 respectively. 

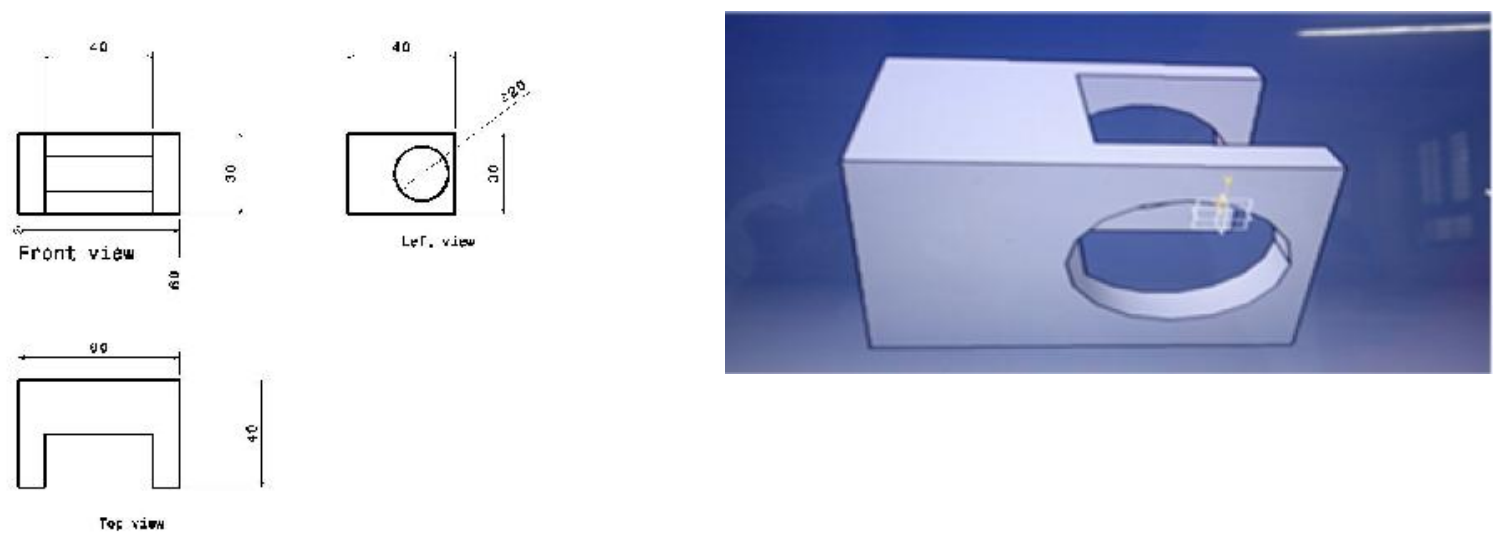

Figure 3(a). 2D drawing of Clamp. (b). 3D drawing of Clamp
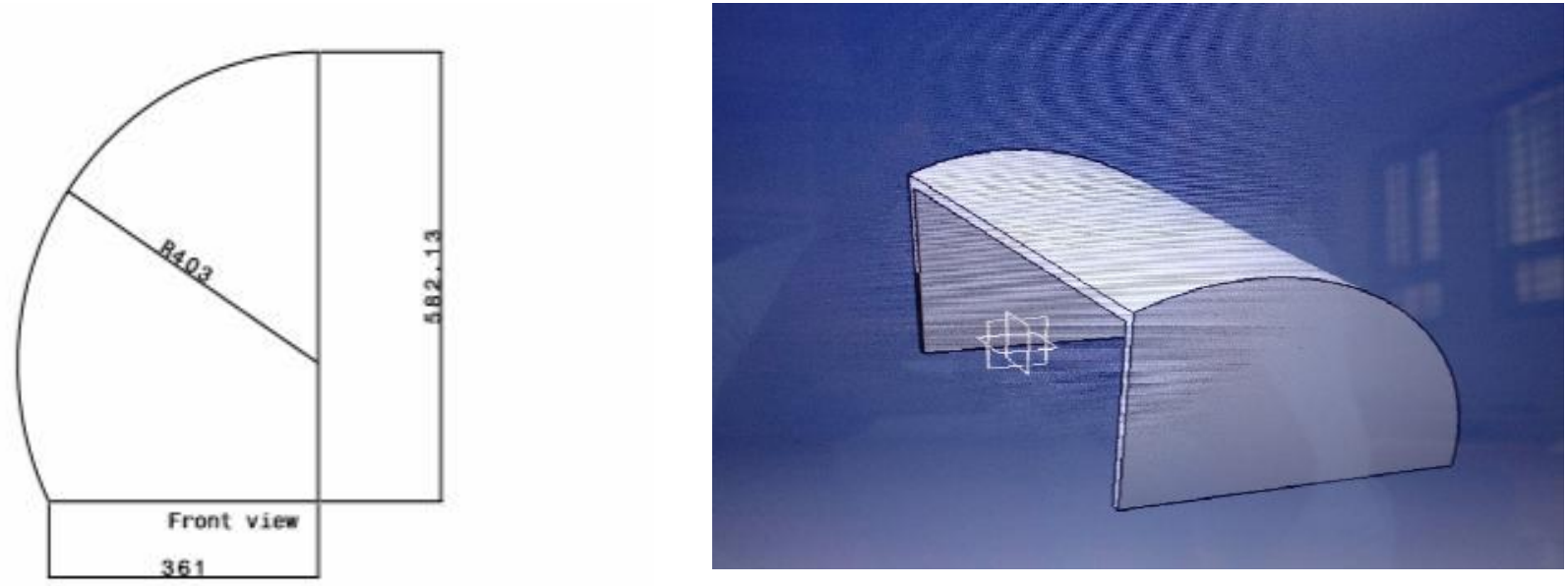

Figure 4(a). 2D drawing of drum cover plate, (b). 3D drawing of drum cover plate.
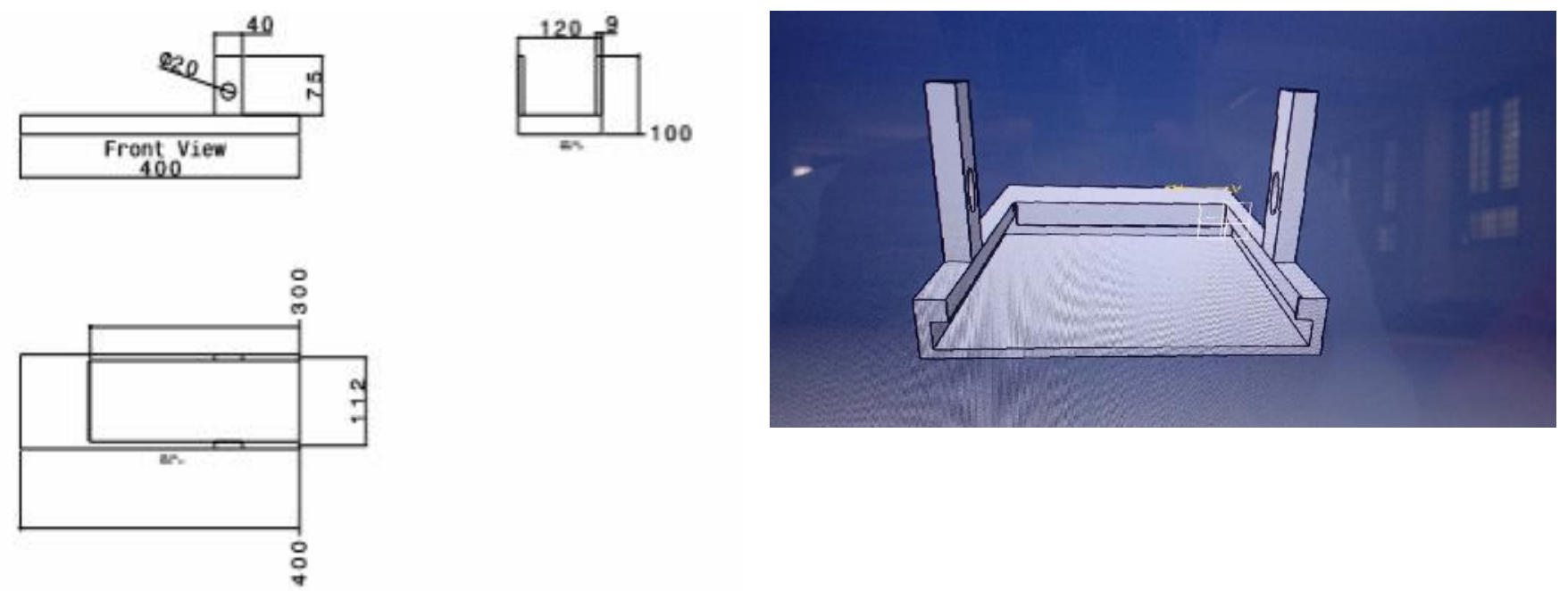

Figure 5(a). 2D drawing of slider, (b). 3D drawing of slider 


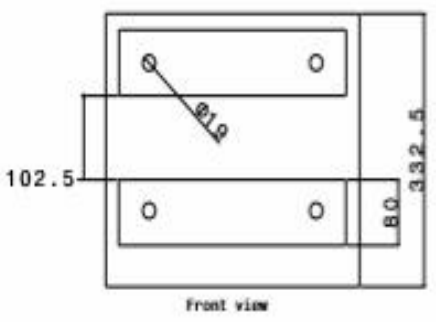

380

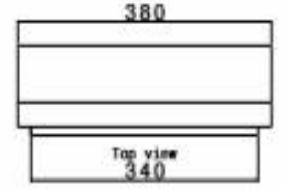

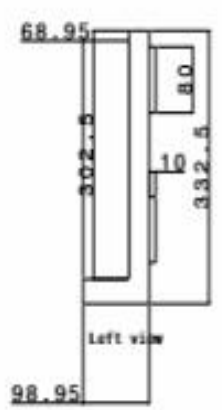

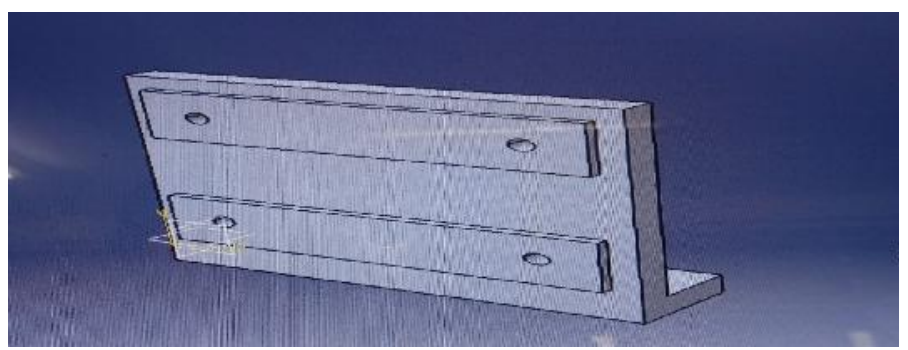

Figure 6(a). 2D drawing of front chassis support, (b). 3D drawing of front chassis support.
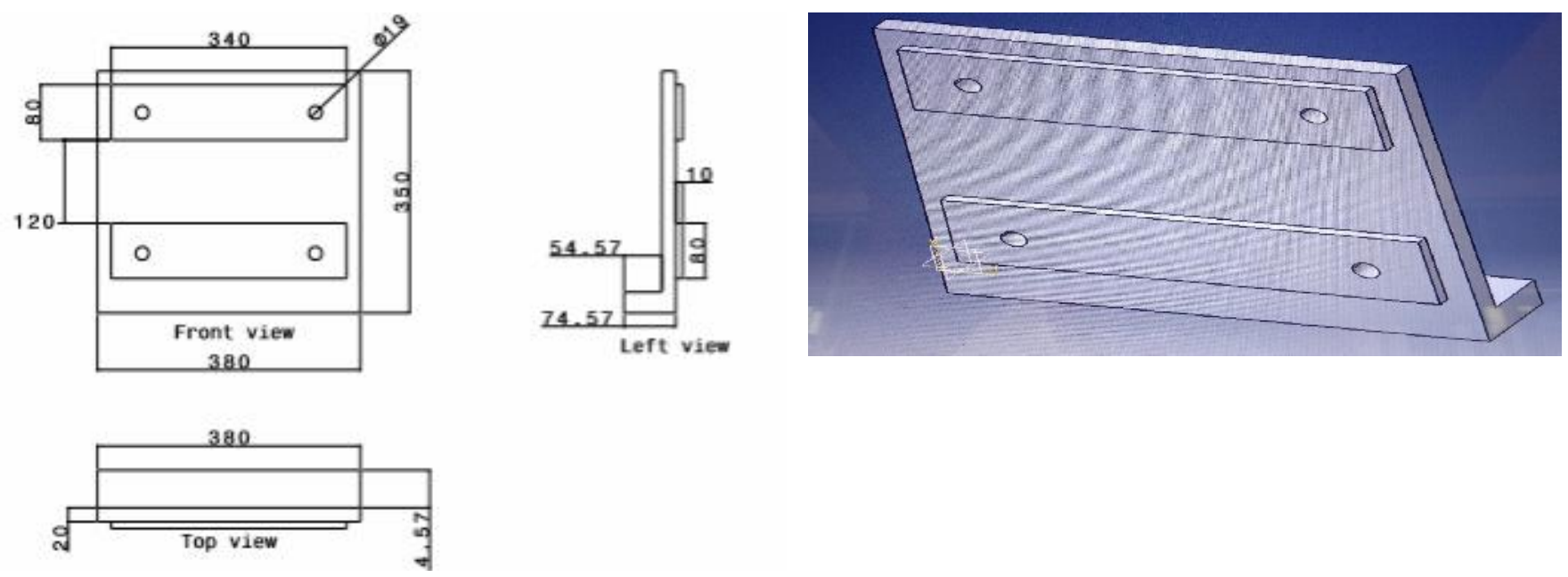

Figure 7(a). 2D drawing of rear chassis support, (b). 3D drawing of rear chassis support.
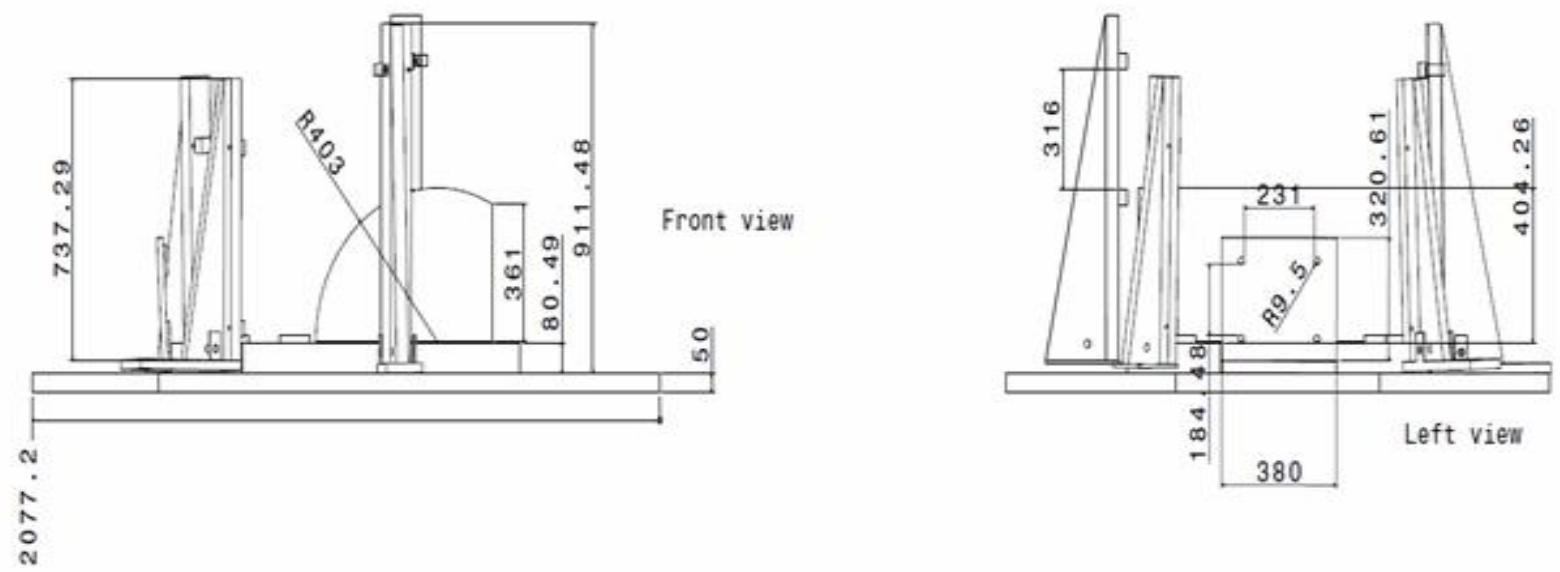

Figure 8. 2D drawing of proposed fixture for front chassis 


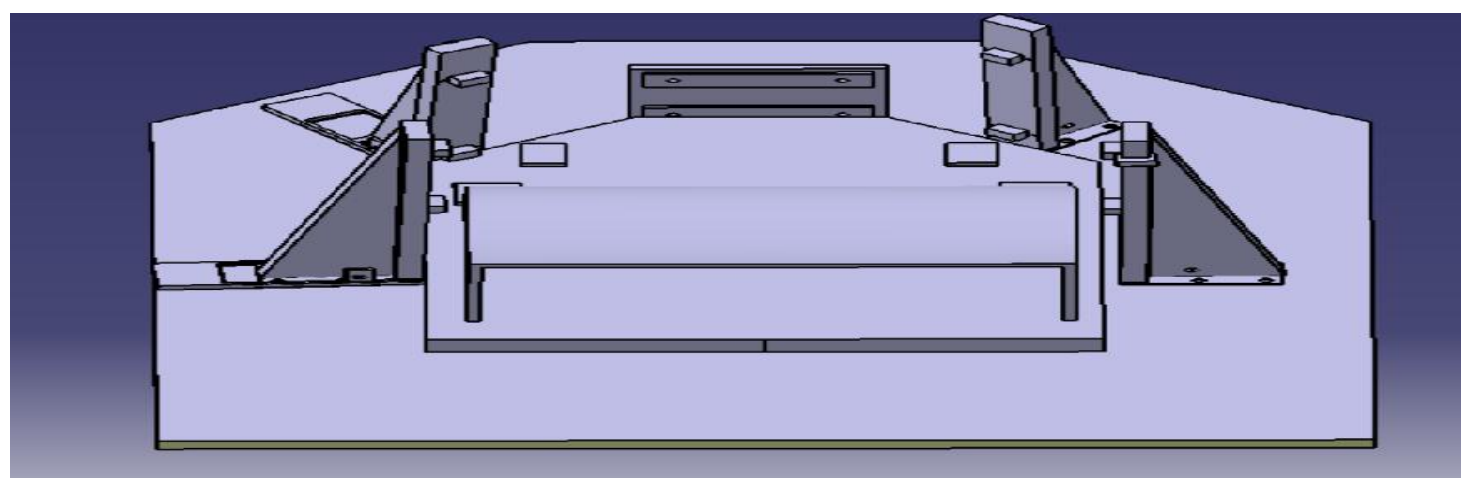

Figure 9. 3D drawing of proposed fixture for front chassis.

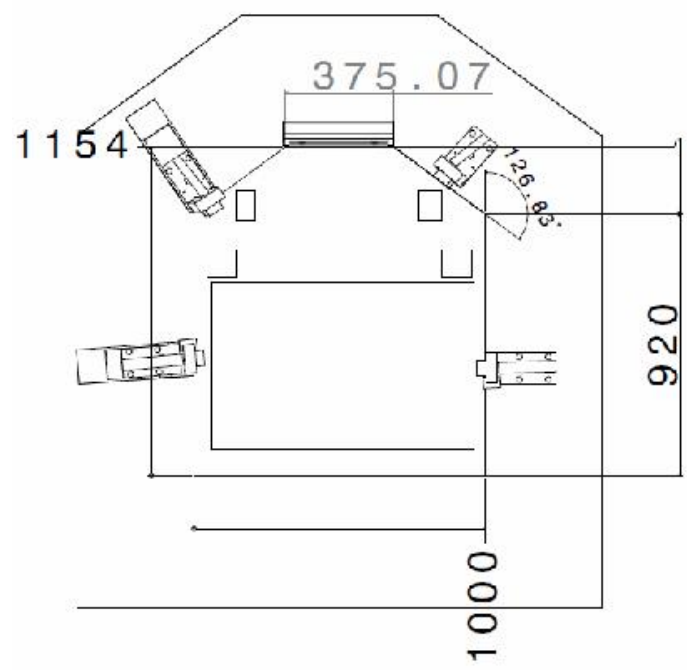

233.95

Figure 10. 2D drawing of proposed fixture for rear chassis

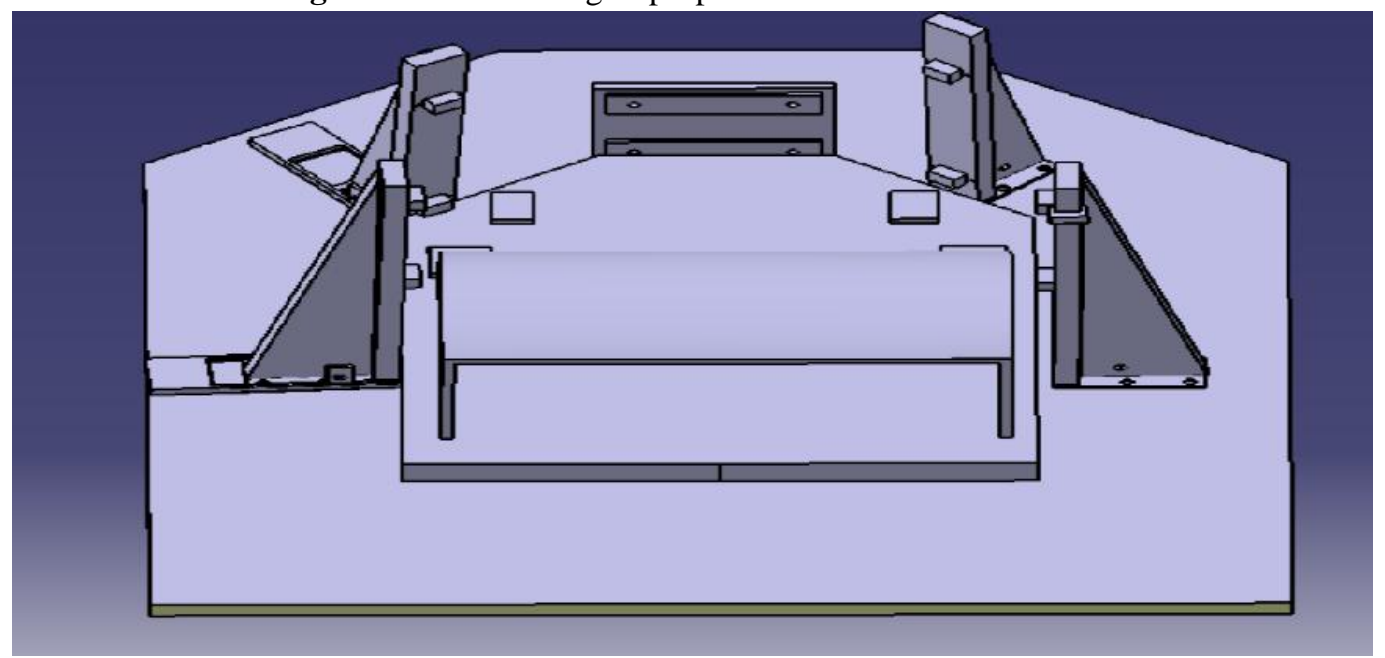

Figure 11. 3D drawing of proposed fixture for rear chassis.

4.1 Cycle time calculations: Once the new design for fixture is proposed, it is then required to quantify its contribution in reducing the cycle time of tack welding operation. The cycle time taken for tack welding process is calculated by considering the time taken for sequence of operations to complete the task. Comparison of cycle time taken for without and with the fixture cases is given in the Table 2. 
Table 2. Comparison of cycle time taken for without and with fixture cases

\begin{tabular}{|l|l|l|l|l|}
\hline \multirow{2}{*}{ Particulars } & \multicolumn{2}{|c|}{ Cycle time in minutes } & $\begin{array}{l}\text { Saving in time } \\
\text { in minutes }\end{array}$ & $\begin{array}{l}\text { \% Saving } \\
\text { in Time }\end{array}$ \\
\cline { 2 - 5 } & Without fixture & With fixture & & \\
\hline Front chassis & 450 & 360 & 90 & 20 \\
\hline Rear Chassis & 510 & 420 & 90 & 18 \\
\hline
\end{tabular}

Different techniques such as lean principles, value stream mapping etc. were found in literature being used to reduce cycle time in manufacturing industry. This case study adds to it by showing how cycle time could be reduced by the proper design of dedicated fixture for tack-welding process.

\section{Conclusion}

In the manufacturing of 4Ton compactors it was found that the fixtures were not utilized properly for the tack welding operation of components of the front and rear chassis. This led to increased cycle time and reduced productivity. Hence it was decided to design a dedicated fixture so as to expedite tack welding operation. The fixtures were designed using 3-2-1 principle and models were generated using CATIA modeling software. When this dedicated fixture was used it was possible to achieve substantial saving in set-up time because it eliminated marking for each job and positioning by trial and error method. As a result, the cycle time for front chassis was reduced by $20 \%$ and rear chassis by $18 \%$. Benefits of this new fixture are twofold. Set-up time is one of the components of cycle time and saving in set-up time contributes to reduction in the cycle time. This subsidizes to increase in the productivity of 4Ton compactor so that the increasing demand rate can be met. Second benefit is that proposed fixture eliminates marking for each job, positioning by trial and error method and hence calls for semiskilled labor instead of skilled labor, reducing labor cost for improved production rate. Additionally on the usage of fixture it was observed that production of defective components was also reduced.

\section{References}

Al-Shayea A., El-Tamimi A., Al-Saleh K. \& Al-Yami K., 2011. Productivity improvement model without increasing operation's risk and fatigue. Engineering, Vol. 3, No.11, pp.1124-1131

Antil P. \& Budhiraja A., 2013. A case study on tool and fixture modification to increase the productivity and to decrease the rejection rate in a manufacturing industry. International Journal of Advance Research in General Science and Engineering, Vol.2, No.9, pp.180-188.

Deshmukh P.A. \& Humbe A.B., 2014. Productivity improvement-a case study. IMPACT: International Journal of Research in Engineering \& Technology, Vol.2, No.2, pp.287-294.

Diaz I.C., Jin Y., Ares E., 2017. Cycle time study of wing spar assembly on aircraft factory, Procedia Manufacturing, Vol. 13, pp. 1019-1025.

Han K.H., Lee G. \& Choi S.H., 2013. Manufacturing cycle time reduction for batch production in a shared worker environment. International Journal of Production Research, Vol.51, No.1, pp.1-8.

Kumar S.S., Kumar M.P., 2014. Cycle time reduction of a truck body assembly in an automobile industry by lean principles, Procedia Materials Science, Vol. 5, pp. 1853-1862.

Malik S., Pahwa N. \& Malik V, 2011. Implementation of cycle time reduction technique in industry, International Journal of Manufacturing Science and Engineering, Vol. 2, No. 2, pp.81-83.

Mengawade S.P., Bankar V. \& Chaphale P.P., 2016. Design and analysis of work holding fixture, International Journal of Scientific Research \& Development, Vol. 4, No. 06, pp.81-83.

Miller D.K., 2003. Welding innovation, Technical Papers for Advanced Welding Education, Vol. 20, No.1, pp.1-21.

Mishra R, 2015. Productivity improvement in automobile industry by using method study, International Journal of Scientific Engineering and Applied Science, Vol. 1, No.4, pp.361-363

Mouhamadou A. Diop, Chen Xiaomeng, Mohamed I. HassanBillets, 2017. Heat treatment using flue gas for energy efficiency and batching cycle time reduction, Energy Procedia, Vol. 105, pp. 3377-3383.

Muvunzi R., Dimitrov D. M., Matope S., Harms T. M., 2018. Development of a model for predicting cycle time in hot stamping, Procedia Manufacturing, Vol. 21, pp. 84-91

Naveen B. \& Ramesh Babu T., 2015. Productivity improvement in manufacturing industry using industrial engineering tools,

Journal of Mechanical and Civil Engineering, Vol.6, No.1, pp.11-18.

Oroumieh M.A.Z., Malaek S.M.B., Ashrafizaadeh M., Taheri S.M., 2013. Aircraft design cycle time reduction using artificial intelligence, Aerospace Science and Technology, Vol. 26, No. 1, pp.244-258.

Vinay T.D., Shivakumar, Karthik Y.C.\& Madhu S., 2015. Design \& analysis of tack welding fixtures for the parts of compactor, International Journal of Engineering Research and General Science, Vol. 3, No.4, pp.396-409. 
Wang X., Puri V.M., Demirci A., Graves R.E., 2016. Mathematical modeling and cycle time reduction of deposit removal from stainless steel pipeline during cleaning-in-place of milking system with electrolyzed oxidizing water Journal of Food Engineering, Vol. 170, pp. 144-159.

\section{Biographical notes}

B. Lathashankar has graduated in Industrial \& Production from Siddaganga Institute of Technology, Tumakuru, affiliated to Bangalore University, Bangalore, (Karnataka), India in 1991, acquired M.Sc (Engg) by Research from Visvesvaraya Technological University, Belagavi, (Karnataka), India in the year 2008 and received Ph.D. degree from Kuvempu University, Shimoga in Supply Chain Optimization. She has 5 years of industrial experience, 18 years of teaching experience and 7 years of experience in research. Currently she is serving as an Associate Professor in Industrial Engineering and Management department at Siddaganga institute of Technology, Tumkur, Karnataka, India. She has published 15 papers in National/International journals and presented 16 papers in conferences.

G. Ashritha, S. Asma, K. Shivam and K. Nitesh are students of the Department of Industrial Engineering and Management, Siddaganga Institute of Technology, Tumkur, India

Received May 2018

Accepted June 2018

Final acceptance in revised form July 2018 